\title{
Behavioral response of larval Atlantic menhaden Brevoortia tyrannus (Latrobe) and spot Leiostomus xanthurus (Lacépède) to rates of salinity change
}

\author{
M.C. De Vries ${ }^{a}$,*, R. B. Forward, Jr. ${ }^{a}$, W.F. Hettler ${ }^{b}$ \\ a Duke University Marine Laboratory, School of the Environment, 135 Duke Marine Lab Rd., Beaufort. \\ NC 28516-9721, USA \\ ${ }^{\mathrm{b}}$ Beaufort Lahoratory, Southeast Fisheries Science Center, National Marine Fisheries Service, NOAA, \\ Beaufort. NC 28516-9722, USA
}

Received 21 April 1994; revision received 18 August 1994; accepted 29 August 1994

\begin{abstract}
Larval Atlantic menhaden [Brevoortia tyrannus (Latrobe)] and spot [Leiostomus xanthurus) (Lacépède)] are transported from the western Gull Strean edge to bays and estuaries of the southeastern United States. Direction of water flow on the continental shelf varies with depth, allowing the potential for enhancement of shoreward transport by behavioral depth regulation, possibly in response to vertical salinity gradients. Salinity profiles from the North and South Carolina continental shelf were analyzed to quantify the salinity gradients in the field. Behavioral response to salinity was investigated by exposing laboratory spawned and reared menhaden and spot larvae of different ages to rates of salinity change in an experimental apparatus in the laboratory. At each rate of salinity change tested, five replicate runs were recorded each with groups of 30 to 50 larvae. Both species and age groups showed a significant ascent response upon salinity increases. Rates of increase of 0.28 and $0.13 \times 10^{-1} \mathrm{ppt} \cdot \mathrm{min}^{-1}$ with absolute salinity increases of 0.8 and $0.3 \mathrm{ppt}$ were thresholds for response by young (4-13 days post-hatching) and old (2-4 wk post hatching) menhaden larvae, respectively. For spot, rates of increase of 1.15 and $0.85 \times 10^{1} \mathrm{ppt} \cdot \mathrm{min}^{1}$ with absolute salinity increases of 1.4 and $2.0 \mathrm{ppt}$ were thresholds for response by young and old larvae, respectively. Response to decreasing salinity was absent in both species, thus decreasing salinity with depth would not cause larvae to descend. In nature, salinity gradients of sufficient magnitude for depth regulation, and possibly facilitating cross-shelf transport appear common for menhaden, but not for spot.
\end{abstract}

Keywords: Gulf Stream; Larval tish; Menhaden (Brevoortia tyrannus); Salinity change; Spot (Leiostomus xanthurus)

\footnotetext{
* Corresponding author.
} 


\section{Introduction}

Recruitment success of estuarine dependent fish, such as the commercially important Atlantic menhaden [Brevoortia tyrannus (Latrobe)] and spot [Leiostomus xanthurus (Laépède)], is believed to depend heavily on transport to nearshore areas by water currents (Nelson et al., 1977; Miller et al., 1984; Norcross \& Shaw, 1984; Warlen \& Chester, 1985; Checkley et al., 1988; Maillet \& Checkley, 1991). Off North Carolina, $\Lambda$ tlantic menhaden and spot spawn primarily during the winter in relatively warm water near the western edge of the Gulf Stream (Weinstein, 1981; Warlen \& Chester, 1985; Checkley et al., 1988; Flores-Coto \& Warlen, 1992). Larvae hatch from eggs within several days, and are transported shoreward tens to over $100 \mathrm{~km}$ to inlets and estuaries over an average of 60 days (Warlen \& Chester, 1985; Hettler \& Chester, 1990; Warlen \& Burke, 1990; Flores-Coto \& Warlen, 1992; Hettler \& Barker, 1993). Transformation to juveniles occurs within estuaries. Proposed advantages of winter spawning include coincidence of larval residence on the shelf with maximum densities of zooplankton prey on the shelf (Weinstein, 1981) and in estuaries after metamorphosis (Warlen \& Burke, 1990), minimum predation rates (Lasker, 1981), and maximum onshore transport of surface to mid-depth waters where larvae are most common while on the outer to mid-continental shelf (Nelson et al., 1977; Maillet \& Checkley, 1991).

The importance of ocean currents and the meteorologic forces affecting them on recruitment and year class strength of marine fishes has been recognized for many years (e.g. Cushing 1975; Miller 1988). Larval fish are generally considered to have sustainable swimming speeds insignificant for transport to nurseries especially as young larvae $\left(1-2\right.$ body lengths $\cdot \mathrm{s}^{-1}=0.5-3.0 \mathrm{~cm} \cdot \mathrm{s}^{-1}$ for larval menhaden and spot $<30$ days old; De Vries, unpubl. data) compared with mean horizontal current speeds on the outer to mid-shelf (2-8 cm·s ${ }^{-1}$; Miller et al., 1984; Checkley et al., 1988). Models of water circulation on the outer to mid-continental shelf of North Carolina during winter differ in complexity, but all stipulate that wind speed and direction are important determinants of circulation patterns inshore of the Gulf Stream (Nelson et al., 1977; Yoder, 1983; Miller et al., 1984; Checkley et al., 1988; Govoni \& Pietrafesa, 1994).

All models show that flow of water above the pycnocline $(\approx 15 \mathrm{~m}$; Checkley et al., 1988 ) is predominantly shoreward over the outer to mid-shelf, either as mean flow or during events such as storms or wind reversals. To compensate for onshore flow of surface waters, deeper waters flow offshore. The model of Miller et al. (1984) shows that under mean winter wind conditions a third, thin layer $(?-5 \mathrm{~m})$ of water, generally colder and less saline, flows offshore at the surface. We employ no particular model in this paper, but rather focus on the predominance of shoreward flow in surface waters of all models. Larvae maximizing their residence in onshore flowing layers should achieve faster onshore transport.

Implicit in such mechanisms of transport enhancement is the ability of the organisms to differentiate water of appropriate current direction from water of inappropriate flow. Field data from the North Carolina coast show that menhaden and spot larvae are in fact associated with specific water masses (Govoni \& Pietrafesa, 1994). Likely cues larvae may be using to avoid offshore-flowing waters include temperature and salinity gradients associated with mid-depth pycnoclines or surface layers. Typically, mid-depth 
pycnoclines would involve salinity increases and temperature decreases with depth (Checkley et al., 1988; Govoni, 1993; unpubl. data, NOAA/NMFS, Beaufort Laboratory). Offshore flowing surface layers are expected to be less saline, and either warmer or colder depending upon weather specifics (Miller et al., 1984).

Normally, zooplankton have a negative feedback system, in which the increase in salinity and decrease in temperature encountered upon descending in the water column evoke an ascent response (Forward, 1987). Similarly, they display a descent response upon exposure to the opposite changes in salinity and temperature, which occur upon moving up (Forward, 1987). Thus, if fish larvae could perceive vertical salinity and temperature gradients and have this negative feedback system, then they could regulate their depth to remain in currents suitable for transport. Larval menhaden and spot densities over the continental shelf appear too variable to provide adequate evidence to support or refute this mechanism of transport (e.g. Kjelson et al., 1976; Nelson et al., 1977; Govoni \& Pietrafesa, 1994). Laboratory experiments, however, show that fish can sense and respond behaviorally to temperature and salinity changes (Westerberg, 1984; Chambalbert et al., 1990, 1992). Laboratory estimates of sensitivities of fish larvae to gradients in these variables would provide evidence on the validity of this mechanism, but have not yet been performed.

Objectives of the present study were twofold: first, to determine the sensitivities of larval menhaden and spot to rates of salinity increase and decrease, and the nature of the behavioral responses to these rates of change; second, to calculate vertical gradients to which larvae should behaviorally respond in the field, and compare them to salinity profiles measured in their habitats. Vertical salinity gradients as well as overall salinity changes throughout the water column may he important in eliciting behavioral responses. Fish larvae were exposed to continuous rates of salinity change in an experimental apparatus in the laboratory. Continuous rates of change rather than step changes were used because they would much more closely approximate what larvae experience in nature as they ascend or descend in the water column. Ontogenetic changes in threshold sensitivities and perceptible salinity gradients were investigated by testing larval fish of two different ages groups.

\section{Materials and methods}

\subsection{Fish culture}

Methods for spawning and larval rearing of menhaden (Brevoortia tyrannus) were as described by Hettler (1981), and of spot (Leiostomus xanthurus) were as described by Hettler \& Powell (1981). After hatching, larvae of both species were held in cylindrical tanks (100 l) at $\approx 20^{\circ} \mathrm{C}$, with ambient salinities of estuarine water (28-33 ppt; Newport River Estuary, North Carolina), and a 12:12 L/D cycle. For experimental purposes, fish were grouped into young (4 to 14 days post-hatching) and old (2-4 wk post-hatching) larvae. Larvae $<30$ days old would be most common on the outer to mid-continental shelf (Warlen \& Chester, 1985; Flores-Coto \& Warlen, 1992; Warlen, 1992). 


\subsection{Experimental apparatus and approach}

The basic experimental procedure was to place groups of fish larvae (30-50 individuals of identical age) into an apparatus which exposed them to different rates of salinity change. The test apparatus was a cylindrical chamber made of clear Plexiglas, and having three horizontal sections (section height $=5.5 \mathrm{~cm}$, diameter $=5.5 \mathrm{~cm}$; Fig. 1). Larvae were confined to the middle section by plankton netting ( $75 \mu \mathrm{m}$ mesh) at the upper and lower boundaries. Larval behavior was monitored and recorded by video; larvae were backlit with far-red light (maximum transmission $775 \mathrm{~nm}$ ). Fish are insensitive to light of this wavelength (Munz 1958; Blaxter, 1969). During experimentation, water flow through the apparatus was created by a variable speed peristaltic pump. Tubing of identical diameter (inside diameter $=1.59 \mathrm{~mm}$ ) was inserted into the bottom and top sections of the apparatus and fed through the same pump. With this design, water depth in the chamber did not change throughout an experiment, and thus hydrostatic pressure remained constant. The direction of water flow could be from bottom to top, or vice-versa, by switching the direction of the pump. To more accurately simulate field conditions, decreases in salinity were tested with the flow of lower

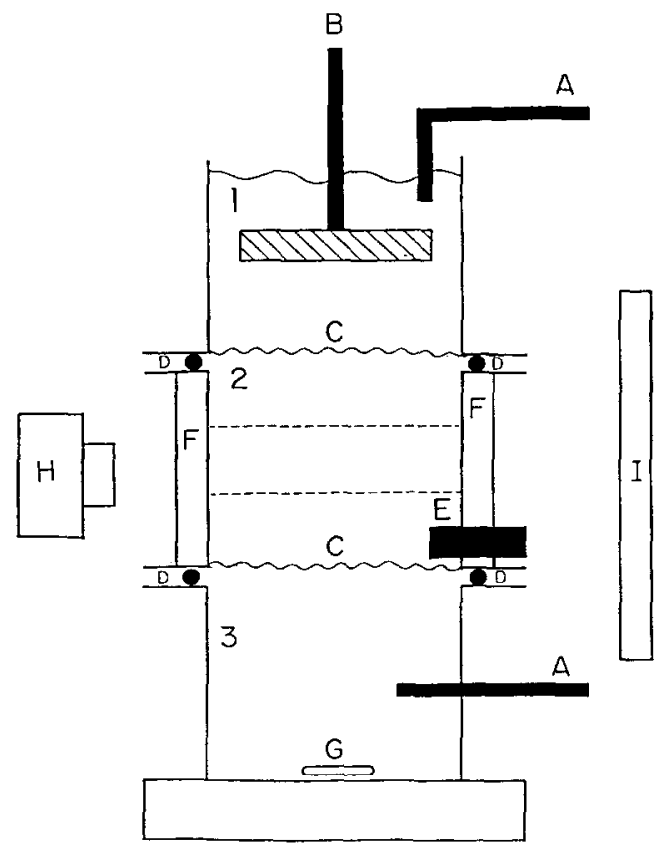

Fig. 1. Vertical view of the test chamber consisting of equal size cylindrical upper (1), test (2), and lower (3) sections (not drawn to scale). A: Fluid input/output tube connected to the peristaltic pump; B: stirring paddle connected to a variable speed stirring motor; $\mathrm{C}$ : $75 \mu \mathrm{m}$ mesh plankton netting; D: $\mathrm{O}$-ring; E: conductivity probe connected to meter with digital readout; $F$ : rectangular water-filled chamber surrounding the test chamber; G: magnetic stirring bar; H: video camera; I: far-red illumination light. In the chamber the video camera and conductivity probe are oriented perpendicular to each other. Dashed lines indicate the three subsections into which the middle section was divided for data analysis. 
salinity water from the top, and increases in salinity were tested with flow of higher salinity water from the bottom. The effect of salinity decreases on old larvae were not tested due to the lack of response of young larvae, and the difficulty of rearing larvae (especially spot) to this older age.

Rates of change in salinity were created by differences between salinity of acclimation and inflow water. In order to minimize the possible confounding effects of changing olfactory cues with salinity changes, water in which larvae were cultured served for both acclimation and inflow water. Salinity of the inflow water was altered with deionized water or Instant Ocean. The magnitude of the rate of change was varied by changing the salinity difference between inflow and acclimation water and the pump speed. The actual salinity in the middle section of the test apparatus was measured with a conductivity probe (Model PP1042; Radiometer), which was calibrated with water of known salinities and temperatures. Maximum salinities created in the test chamber were not greater than $35.5 \mathrm{ppt}$, in which larvae remained negatively buoyant.

A stir-bar slowly mixed water in the bottom section when water entered this section. Similarly, when water flowed into the top, a paddle-type stirrer, connected to a variablespeed motor, was lowered into the upper section. Constant mixing of the inflow water with the acclimation water in the upper or lower sections of the chamber provided a relatively uniform rate of salinity change for each flow rate/salinity difference condition tested. Dye studies indicated that the flow of water in the middle section of the chamber was approximately laminar. Actual rates of salinity change were calculated using the conductivities recorded with the conductivity probe. The digital readout of conductivity was viewed by a second camera and inserted on the videotape with a video screen splitter (V270SP; Vicon). A record of time was also inserted on the picture by a time/date generator (WJ-810; Panasonic). In this way, larval behavior, conductivity, and time were simultaneously recorded on videotape. The salinity rates of change for the experiments were calculated from the time and conductivity rccords.

During the experiments, water in the test chamber increased in temperature slightly (generally $0.2-0.8^{\circ} \mathrm{C}$, depending upon the duration of the run), probably due to the combined influence of the peristaltic pump and magnetic stirring motor. These rates of temperature increase alone were not found to cause behavioral responses in menhaden larvae (De Vries et al., in review). Temperature at the beginning and end of each experiment was measured by a thermistor inserted in the top section. In this way, the contribution of temperature change to the conductivity change could be calculated. This yielded a more accurate estimate of rate of salinity change.

\subsection{Experimental procedure}

Fish larvae for experimentation were obtained daily from the rearing tanks. For each experimental replicate, a group of larvae was placed into the chamber with their acclimation water. After the inflow/outflow tubing was connected, and the stirrer turned on, the lights were turned out and the larvae were allowed to dark adapt for 5 min before the pump was turned on. Video recording began immediately thereafter.

Length of experiments $(20 \mathrm{~min}$ to $1 \mathrm{~h})$ varied directly with rate of salinity change; the slower the rate of change, the longer the experiment. Five or six replicates, with 
different groups of fish were run for each test rate of salinity change. All experiments were run between 0930 and 1730 . To control for responses of larvae to flow through the chamber, and the small temperature increases observed during experimentation, larvae were tested with inflow of acclimation water at the highest and lowest flow rates for which a significant behavioral response was observed. All experiments were conducted in darkness.

\subsection{Analysis}

To analyze for behavioral responses, the middle section of the test chamber was divided horizontally into three equal subsections. The number of larvae in each of the subsections was counted at the beginning of each run, and after predetermined changes in salinity. The salinity increment utilized for analysis varied directly with rate of salinity change from $0.1 \mathrm{ppt}$ to $0.5 \mathrm{ppt}$ for slowest and fastest rates of salinity change, respectively. This approach was taken in an attempt to equalize the number of sampling times among treatments. Control tapes were analyzed using mean times to each salinity increment as calculated from the salinity change tapes, with rates of water inflow corresponding to each control. Larvae in each subsection of the test chamber were counted at these times.

The change in the percentage of larvae remaining near the stimulus (i.e. in the bottom subsection for salinity increases and in the top subsection for salinity decreases) was the response variable in these experiments. A Dunnett's test for multiple comparisons (Dunnett, 1964) was used to test for differences in percentage of larvae remaining near the stimulus through the experiment, by comparing each subsequent time interval to the control ( $=$ initial percentage on any run). This analysis better controlled for differences in groups of larvae used in each run. Control runs for the effects of flow and small temperature increases were analyzed in the same manner. Percentages were arcsine transformed.

The lowest rate of salinity change for which a significant behavioral response was observed was considered the threshold rate. This value and the absolute amount of salinity change necessary for a significant response were used to characterize salinity sensitivity. Behavior of fish larvae may be influenced by the magnitude of vertical gradients (calculated from threshold rates) and the overall change in salinity they experience while moving vertically.

\subsection{Salinity gradients on the continental shelf}

Vertical salinity profiles were obtained from four cruises (Jan. 1992, Dec. 1992, Feb. 1993, Feb. 1994) on the North and South Carolina continental shelf conducted by NOAA/NMFS personnel (Southeast Fisheries Science Center, Beaufort, NC). Salinity was measured by a temperature, salinity and depth recorder (Applied Microsystems, Model STD-12). Data were analyzed from 75 stations in areas where spot and menhaden larvae are routinely collected (11-64 m depth; $33^{\circ} 10^{\prime}-34^{\circ} 53^{\prime} \mathrm{N}$ latitude).

Two measures of vertical salinity change were taken from each profile. Maximum change in salinity (ppt) throughout the water column and the maximum vertical gradient 
$\left(\mathrm{ppt} \cdot \mathrm{m}^{-1}\right)$ as measured between any two adjacent $1-\mathrm{m}$ depth intervals was calculated for each station. Data for these two variables were used to determine the number of stations which had salinity gradients and overall salinity changes exceeding laboratory threshold estimates. Cutoffs for ranges of the salinity variables were selected to more easily determine the ecological relevance of the theoretically perceptible salinity gradients and threshold absolute salinity changes measured in the behavioral experiments.

\section{Results}

\subsection{Salinity increase}

Larvae of both species and age groups were extremely sensitive to salinity increases. When presented with rates of salinity increase at or above a minimum (threshold; $0.132-0.282 \times 10^{-1} \mathrm{ppt} \cdot \mathrm{min}^{-1}$ for menhaden, and $0.846-1.146 \times 10^{-1} \mathrm{ppt} \cdot \mathrm{min}^{-1}$ for spot), larvae showed a significant behavioral response (Table 1). Fish larvae ascended in the test chamber throughout most of the experiments with rates of salinity increase

Table 1

Response of laboratory-reared fish larvae to rates of salinity increase

\begin{tabular}{|c|c|c|c|c|}
\hline Species & Age & $\begin{array}{l}\text { Water flow rate } \\
\left(\mathrm{ml} \cdot \min ^{-1}\right)\end{array}$ & $\begin{array}{l}\text { Rate of salinity increase } \\
\left(\times 10^{-1} \mathrm{ppt} \cdot \mathrm{min}^{-1}\right)\end{array}$ & $\begin{array}{l}\text { Threshold absolute } \\
\text { salinity increase (ppt) }\end{array}$ \\
\hline Brevoortia tyrannus & 4-13 days & $\begin{array}{r}3.5 \\
3.5 \\
3.5 \\
3.5 \\
3.5 \\
7.0 \\
10.0 \\
8.5\end{array}$ & $\begin{array}{l}0.120 \\
0.132 \\
0.282^{*} \\
0.384 \\
0.540 \\
1.248 \\
1.380 \\
1.520\end{array}$ & $\begin{array}{l}\text { n.s. } \\
\text { n.s. } \\
0.8 \\
0.2 \\
0.2 \\
0.6 \\
1.4 \\
0.8\end{array}$ \\
\hline B. tyrannus & $2-4$ wk & $\begin{array}{r}3.0 \\
3.0 \\
7.0 \\
10.0\end{array}$ & $\begin{array}{l}0.132 * \\
0.252 \\
1.332 \\
2.502\end{array}$ & $\begin{array}{l}0.3 \\
0.2 \\
0.6 \\
0.2\end{array}$ \\
\hline Leiostomus xanthurus & 4-13 days & $\begin{array}{r}7.0 \\
7.0 \\
8.5 \\
10.0\end{array}$ & $\begin{array}{l}0.636 \\
0.930 \\
1.074 \\
1.146^{*}\end{array}$ & $\begin{array}{l}\text { n.s. } \\
\text { n.s. } \\
\text { n.s. } \\
1.4\end{array}$ \\
\hline L. xanthurus & $2-4 w k$ & $\begin{array}{r}5.0 \\
7.0 \\
10.0 \\
10.0 \\
15.0\end{array}$ & $\begin{array}{l}0.666 \\
0.846^{*} \\
1.218 \\
1.824 \\
2.130\end{array}$ & $\begin{array}{l}\text { n.s. } \\
2.0 \\
0.9 \\
1.4 \\
2.0\end{array}$ \\
\hline
\end{tabular}

Asterisks designate the minimum (threshold) rates of salinity increase necessary for a significant $(p<0.05)$ ascent response. Threshold absolute salinity increase is the minimum salinity change for a significant ascent response. All rates above threshold evoked an ascent response. n.s. indicates a rate did not evoke a significant response. 
at and above threshold (Fig. 2). This response was not due to water flow or the slight temperature increase during experimentation, as control runs at equal or slightly faster flow rates showed no significant change in the proportion of larvae in the bottom subsection of the chamber over similar amounts of time (Fig. 3).

Menhaden larvae were more sensitive, by a factor of $\approx 5$, to rates of salinity increase than were spot larvae. For both species, older larvae were more sensitive than young larvae (Fig. 2; Table 1). Old menhaden larvae were so sensitive to rates of salinity increase that their thresholds were below rates reliably produced by the apparatus $\left(\approx 0.12 \times 10^{-1} \mathrm{ppt} \cdot \mathrm{min}^{-1}\right)$. At threshold rates of salinity increase, menhaden larvae were more sensitive to absolute increase in salinity $(\geq 0.3 \mathrm{ppt})$ than were spot larvae $(\geq 1.4 \mathrm{ppt})$. Ontogeny had no clear effect on absolute amount of salinity increase necessary to elicit a response at threshold rates of salinity increase. Old menhaden larvae responded at lower absolute salinity increases than young menhaden, but young spot larvae responded at lower absolute salinity increases than old spot larvae (Table 1). For salinity increase rates at and above threshold, there appeared to be no clear relationship between rate of salinity increase and absolute amount of salinity increase necessary to elicit a response among all types of larvae tested (Table 1).

The vertical salinity gradients theoretically perceptible to larvae sinking in the water

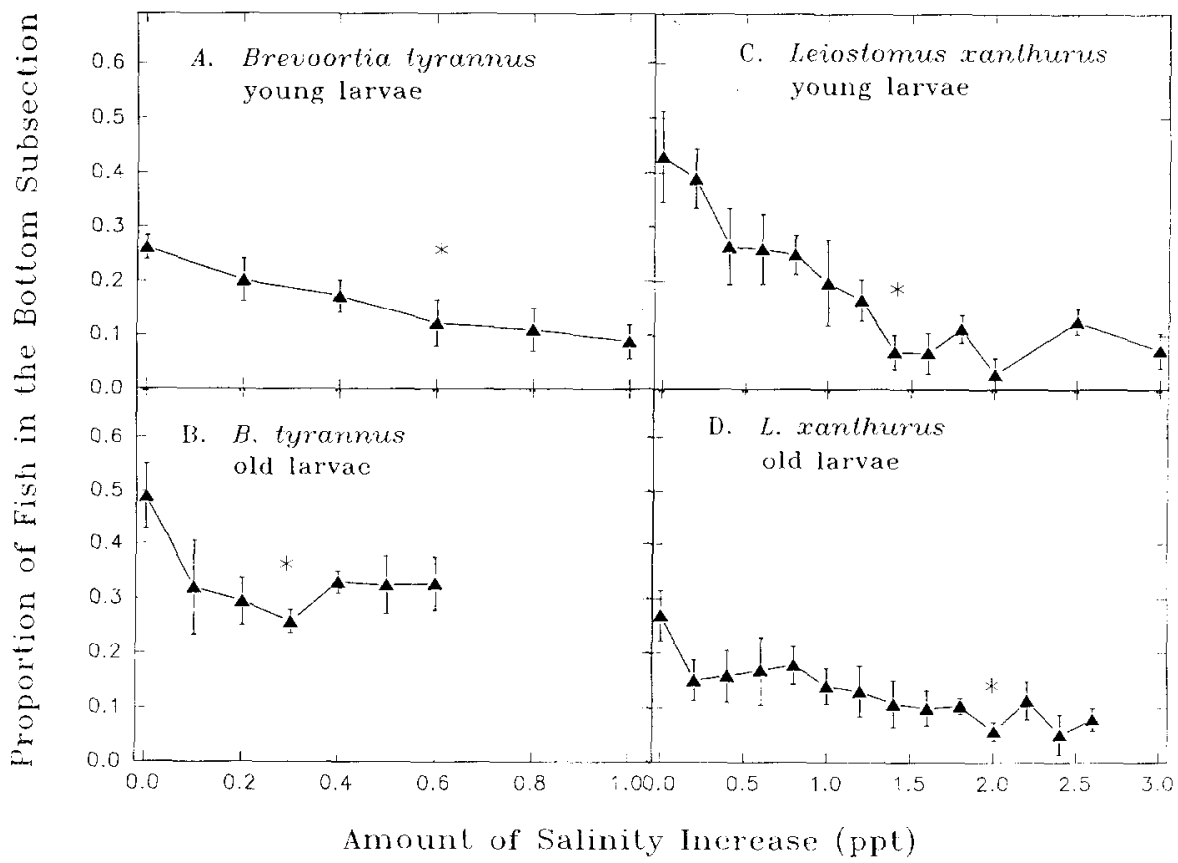

Fig. 2. Proportion of laboratory-reared larval fish aggregating in the bottom subsection of the test chamber upon stimulation with threshold rates of salinity increase. Asterisks show the minimum absolute amount of salinity increase at which a significant $(p<0.05)$ bchavioral response was observed (threshold absolute salinity increase). Rate of increase for $(A)=0.28 \times 10^{-1} \mathrm{ppt} \cdot \min ^{-1} ;(B)=0.13 \times 10^{1} \mathrm{ppt}^{-\mathrm{min}^{-1}} ;(\mathrm{C})=$ $1.15 \times 10^{-1} \mathrm{ppt} \cdot \mathrm{min}^{-1} ;(\mathrm{D})=0.85 \times 10^{-1} \mathrm{ppt} \cdot \mathrm{min}^{-1}$. Triangles designate means of $5-6$ replicates with $30-$ 50 larvac each; error bars are standard errors. 


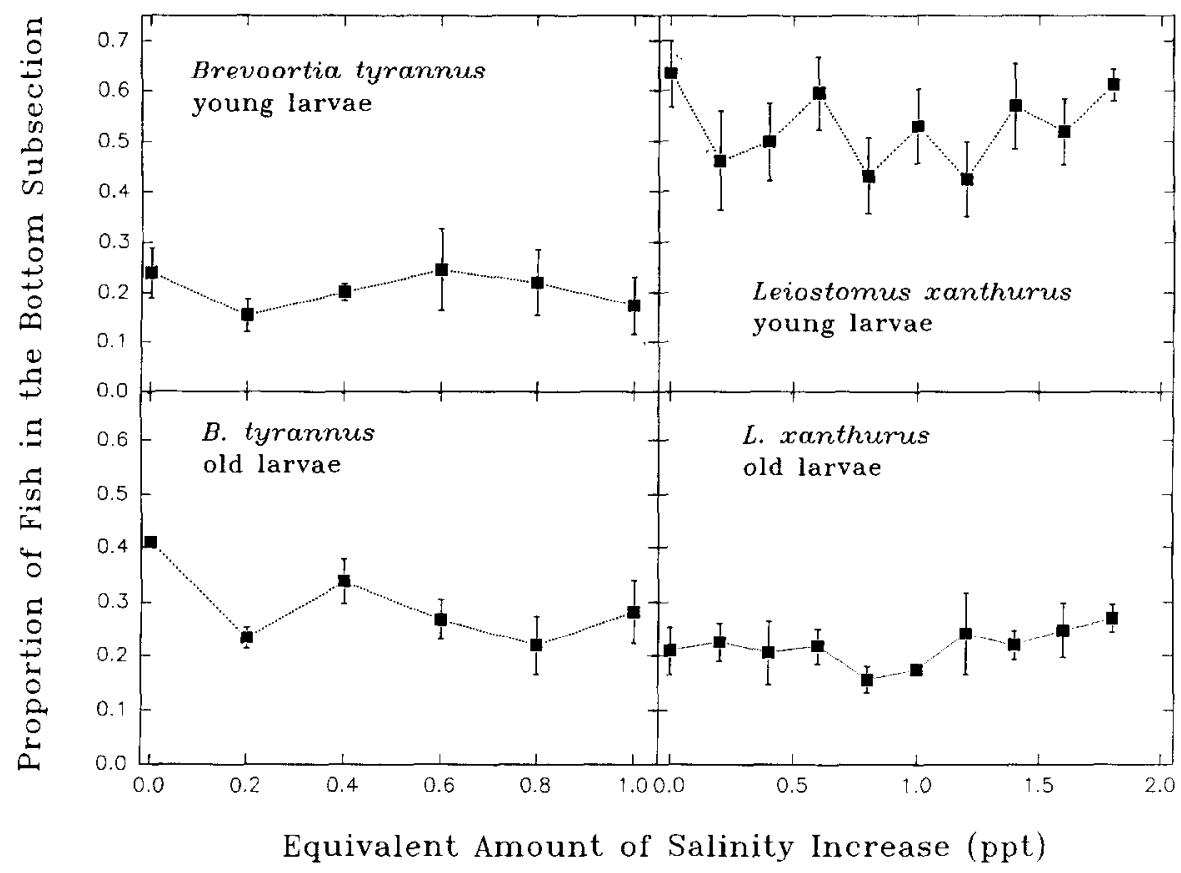

Fig. 3. Proportion of laboratory-reared larval fish aggregating in the bottom subsection of the test chamber for control runs with flow from the bottom. Inflow water was of the same salinity as acclimation water in the chamber. Water flow rates were $3 \mathrm{ml} \cdot \mathrm{min}^{-1}$ for Brevoortia tyrannus and $10 \mathrm{ml} \cdot \mathrm{min}^{-1}$ for Leiostomus xanthurus. These flow rates are equal to or greater than those used for the threshold rates of salinity increases (Fig. 1). The times of behavioral observations for controls were calculated from mean observation times for the salinity increase experiments having the same water inflow rates. Thus, the abscissa units represent amounts of salinity change equivalent to those in Fig. 1, in terms of elapsed time. Squares designate means of 5-6 runs with 30-50 larvae each; error bars are standard errors.

column of the continental shelf were calculated by dividing the threshold rate of salinity change for each age group and species (Table 1) by estimates of larval descent speeds. Descent speeds, or sinking rates of larvae are variable and depend upon larval size, degree of swim bladder inflation, and larval attitude (deviation from horizontal body position; Hoss et al., 1989). Speeds $\leq 9 \mathrm{~mm} \cdot \mathrm{s}^{-1}$ would be expected for larvae less than one month old. As with thresholds for salinity gradients, larval menhaden should be more sensitive to increasing vertical salinity gradients than spot (Table 2). Young menhaden larvae should respond to gradients from $\approx 0.05$ to $0.5 \mathrm{ppt} \cdot \mathrm{m}^{-1}$, and old menhaden larvae should respond to salinity gradients from $\approx 0.02$ to $0.2 \mathrm{ppt} \cdot \mathrm{m}^{-1}$. Spot would only be capable of responding to much higher gradients, from $\approx 0.2$ to $2.0 \mathrm{ppt} \cdot \mathrm{m}^{-1}$ (Table 2 ).

\subsection{Salinity decrease}

Neither young menhaden, nor young spot larvae, displayed a descent response to salinity decreases at rates ranging from 1.6 to $4.1 \times 10^{-1} \mathrm{ppt} \cdot \mathrm{min}^{-1}$ (Table 3 ). For 
Table 2

Salinity gradients detectable by fish larvae with threshold sensitivities (Table 1) at a range of descent speeds

\begin{tabular}{|c|c|c|c|c|}
\hline \multirow{3}{*}{$\begin{array}{l}\text { Descent speed } \\
\left(\mathrm{mm} \cdot \mathrm{s}^{-1}\right)\end{array}$} & \multicolumn{4}{|c|}{ Detectable increasing salinity gradients $\left(\mathrm{ppt} \cdot \mathrm{m}^{-1}\right)$} \\
\hline & \multicolumn{2}{|c|}{ Brevoortia tyrannus } & \multicolumn{2}{|c|}{ Leiostomus xanthurus } \\
\hline & 4-13 days & $2-4 w k$ & 4-13 days & $2-4$ wk \\
\hline 1 & 0.47 & 0.22 & 1.91 & 1.41 \\
\hline 3 & 0.16 & 0.07 & 0.637 & 0.47 \\
\hline 5 & 0.094 & 0.044 & 0.382 & 0.282 \\
\hline 7 & 0.067 & 0.031 & 0.273 & 0.201 \\
\hline 9 & 0.052 & 0.024 & 0.212 & 0.157 \\
\hline
\end{tabular}

Gradients were calculated by dividing observed thresholds for salinity rates of change (Table 1 ) by a range of estimated descent speeds for fish larvae $<1$-month-old. Descent speeds were based on sinking rates of Brevoortia tyranmis larvae (Hoss et al., 1989).

Table 3

Response of laboratory-reared fish larvae to rates of salinity decrease

\begin{tabular}{lllll}
\hline Species & Age & $\begin{array}{l}\text { Water flow rate } \\
\left(\mathrm{ml} \cdot \mathrm{min}^{-1}\right)\end{array}$ & $\begin{array}{l}\text { Rate of salinity decrease } \\
\left(\times 10^{-1} \mathrm{ppt} \cdot \mathrm{min}^{-1}\right)\end{array}$ & $\begin{array}{l}\text { Threshold absolutc } \\
\text { salinity decrease (ppt) }\end{array}$ \\
\hline Brevoortia tyramus & $4-13$ days & 15 & 4.13 & n.s. \\
Leiostomus xanthurus & $4-13$ days & 5 & 1.62 & n.s. \\
& 10 & 1.85 & n.s. \\
& 7 & 2.61 & n.s. \\
\hline
\end{tabular}

example, when presented with the fastest salinity decrease rate of $4.1 \times 10^{-1} \mathrm{ppt} \cdot \mathrm{min}^{-1}$, the proportion of fish in the top section of the chamber did not change significantly over an absolute salinity decrease of $2.5 \mathrm{ppt}$ (Fig. 4). This rate should have evoked a response, since it is nearly twice that of the highest rates of salinity increase tested (Table 1). Furthermore, if larvae were ascending at $5 \mathrm{~mm} \cdot \mathrm{s}^{-1}$, this rate of change would be encountered in the very large salinity gradient of $1.4 \mathrm{ppt} \cdot \mathrm{m}^{-1}$.

\subsection{Salinity gradients on the continental shelf}

A net salinity increase with depth was observed at $75 \%$ of the stations examined. Maximum gradients of increasing salinity with depth were always greater than 0.025 $\mathrm{ppt} \cdot \mathrm{m}^{-1}$, and usually were between 0.051 and $0.200 \mathrm{ppt} \cdot \mathrm{m}^{-1}$ (Fig. 5A). At only one station was a salinity gradient above $1.0 \mathrm{ppt} \cdot \mathrm{m}^{-1}$ observed. Absolute increases in salinity with depth showed a different distribution pattern. Small absolute increases in salinity were observed most frequently, with increases less than $0.800 \mathrm{ppt}$ observed at $65 \%$ of all stations analyzed (Fig. 5B). At only one station was an increase greater than $1.399 \mathrm{ppt}$ observed over the water column. 


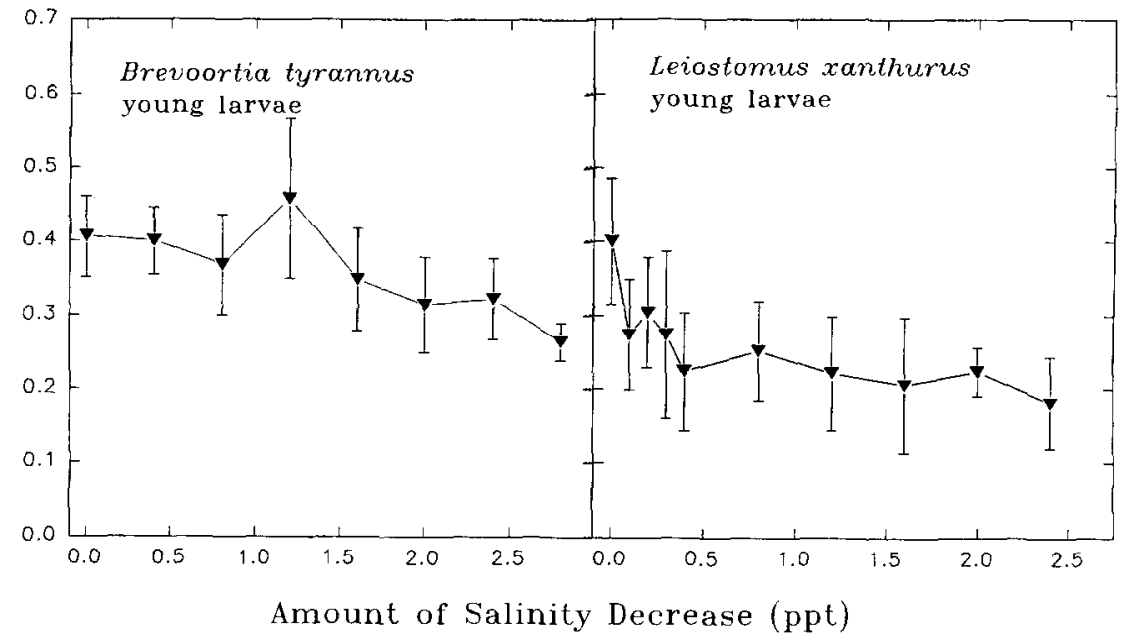

Fig. 4. Proportion of laboratory-reared larval fish aggregating in the top section of the test chamber upon stimulation with high rates of salinity decrease $\left(\approx 4 \times 10^{-1} \mathrm{ppt} \cdot \mathrm{min}^{-1}\right)$. Triangles designate means of 5-6 runs with 30-50 larvae each; error bars are standard errors.

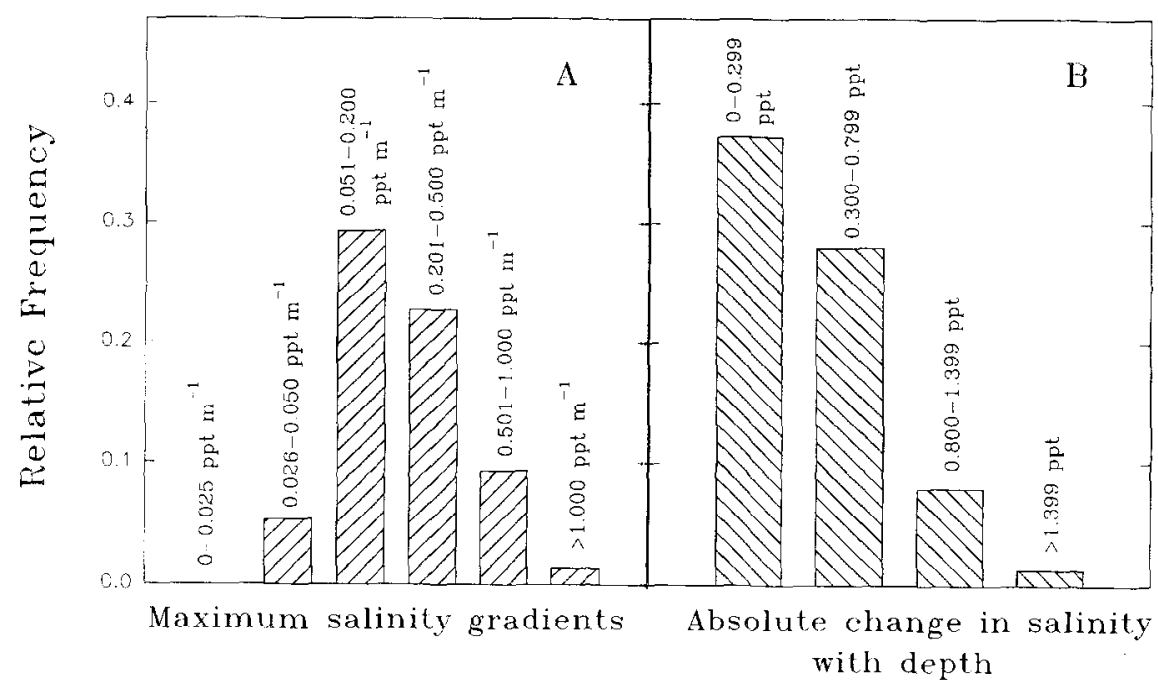

Fig. 5. Relative frequencies of salinity characteristics at the 56 stations (of 75 examined) having decreasing salinity with depth during winter (Dec. to Feb.) on the North and South Carolina continental shelf. For each station, the maximum salinity gradient as measured between any two adjacent $1-m$ depth intervals (A), and the overall decrease in salinity throughout the water column (B) were obtained from CTD profiles. Average water column depth $=31.0 \mathrm{~m}, \mathrm{SD}=9.3 \mathrm{~m}$. 


\section{Discussion}

Our results show that larval Atlantic menhaden and spot undergo an ascent response when exposed to rates of salinity increase in the laboratory. In the field larvae would typically experience a salinity increase upon descent in the water column which would cause the larvae to swim upwards. Descent responses to a salinity decrease from above were absent in both species, suggesting that gradients of decreasing salinity do not function as cues affecting larval swimming behavior and vertical distribution. Menhaden and spot larvae thus appear to display half of the negative feedback system typically operative for depth regulation, since a salinity increase can function as a barrier for descent. Using salinity gradients to regulate their depth in the water column could maximize larval residence in onshore-flowing waters, and minimize transit time across the continental shelf. Menhaden were more sensitive to salinity increases than spot, suggesting that salinity gradients are more likely functional cues for menhaden than for spot.

Absolute salinity increases with depth sufficient for response by spot larvae ( $\geq 1.4 \mathrm{ppt}$ ) were not observed among the 75 stations examined. In contrast, absolute salinity increases sufficient to evoke ascent responses by young and old menhaden larvae ( $\geq 0.8$ and $0.3 \mathrm{ppt}$ at threshold, respectively) probably occur in most regions on the North and South Carolina continental shelf. Measurements of salinity change throughout the entire water column are probably overestimates of changes experienced by larvae, and as such may be better viewed as potential maxima larvae would encounter. Actual absolute changes experienced by sinking larvae are probably smaller than total water column changes. Given the relatively large threshold for absolute salinity increases necessary for ascent response by spot larvae in the laboratory, and lack of response to salinity decreases, it appears unlikely that larval spot are using salinity gradients to remain within a particular water mass.

Salinity gradients within those theoretically detectable by menhaden larvae over a range of descent speeds were often observed on the continental shelf. Stations with absolute increases sufficient to evoke responses in young and old menhaden always had maximum salinity gradients within the theoretically detectable limits of both age groups of menhaden larvae throughout a range of descent speeds. Thus, salinity gradients and absolute salinity changes which are perceptible to menhaden larvae appear common on the North and South Carolina shelf during winter. If larvae actively swim downwards at speeds greater than sinking rates, then estimates of theoretically perceptible gradients (Table 2) are conservative.

Increased sensitivity of older menhaden larvae, coupled with the greater swimming abilities (Hunter, 1981; Blaxter \& Hunter, 1982; Miller et al., 1985) and sinking rates (Hoss et al., 1989) of larger animals suggest that older menhaden larvae are more likely to respond to salinity gradients, which possibly enhance their shoreward transport. Similar ontogenetic changes in larval sensitivity to physical gradients have been observed for invertebrates (e.g. Forward, 1989). Previous work on larval fish also suggests that the role of larval behavior in determining vertical position in the water column and enhanced larval transport increases with age and size (see Norcross \& Shaw, 1984; Boehlert \& Mundy, 1988; Lawler et al., 1988). 
Responses of fish larvae to rates of salinity change upon acclimation to different salinities were not investigated in this study. Acclimation salinity did not affect the direction nor the magnitude of behavioral responses by larval crustaceans, even with a $10 \mathrm{ppt}$ difference in acclimation salinities (Forward, 1989). Acclimation salinities in the present study varied over 5 ppt. It is unlikely that such small changes in acclimation salinity affected our results. Salinities on the outer- to mid-continental shelf of North Carolina during winter vary less than $5 \mathrm{ppt}$ both vertically and horizontally (e.g. Checkley et al., 1988; Govoni, 1993; Govoni \& Pictrafesa, 1994), thercfore larvac are acclimatized to a very narrow range of salinities.

Results of the present study show a high degree of variability in individual response to rates of salinity change. This variability may contribute toward the imprecise depth distributions observed for spot and menhaden on the North Carolina continental shelf (Kendall \& Reintjes, 1975; Kjelson et al., 1976; Govoni \& Pietrafesa, 1994). Discrete depth plankton samples show substantial spatial and temporal variability in mean depth of both species. This result may be due to vertical mixing, the numerous depth dependent biological interactions (e.g. food availability, predation) affecting distribution and survival of larvae, and inherent variability among individuals. In general, spot larvae are found deeper than menhaden; though primarily within surface to mid-depth waters on the outer to mid-continental shelf, their distribution can extend to the bottom (Kendall \& Reintjes, 1975; Kjelson et al., 1976; Nelson et al., 1977; Checkley et al., 1988; Govoni \& Pietrafesa, 1994). With movement inshore, both species are found closer to the bottom (Kjelson et al., 1976). For menhaden larvae, temporal variability in vertical distribution, and a higher mean position in the water column compared to spot may be related to their diel vertical migration behavior (Hoss et al., 1989; Forward et al., 1993). It would follow that spot larvae, which do not undergo diel vertical migration (Sogard et al., 1987), would likely be abundant somewhat deeper.

Laboratory experiments show that menhaden larvae $(\geq 11 \mathrm{~mm})$ rise to the water's surface at sunset to fill their swim bladders with air (Hoss et al., 1989; Forward et al., 1993). This behavior is believed to increase buoyancy of the larvae at night, allowing them to expend less energy staying in the mid- to upper water column (Hunter \& Sanchez, 1976; Hoss et al., 1989; Forward et al., 1993). At sunrise, air in the swim bladder is expelled, allowing larvae more swimming agility and likely maintenance of a deeper position in the water column (Forward et al., 1994). Results of day and night plankton samples corroborate this hypothesis (Kjelson et al., 1976; Govoni \& Pietrafesa, 1994). The ascent at sunset requires larvae to move into surface waters which may have lower salinity. The absence of a behavioral response to a salinity decrease means that lower salinity surface waters would not inhibit surfacing for swim bladder inflation. Nightly excursions to the water's surface would put larvae in offshore flowing waters during periods of three-layer flow (Miller et al., 1984), though such excursions may be brief.

Models of water circulation on the outer to mid-continental shelf of North Carolina differ from one another partly due to mean wind speeds and directions used to construct the models. Undoubtedly, wind direction off coastal North Carolina varies throughout the winter, and proper conditions for setting up 2-layer (Nelson et al., 1977; Yoder, 1983; Checkley et al., 1988; Govoni \& Pietrafesa, 1994) and 3-layer flows 
(Miller et al., 1984) may occur for different periods of time. This likely accounts for some of the observed variability in oceanographic data and larval fish distributions. Though sloping isohalines have been observed on the outer shelf (Govoni, 1993), available data are inadequate to determine whether vertical salinity gradients are predictably associated with interfaces between onshore and offshore flow. Such information is needed to support or to refute proposed mechanisms of larval depth regulation.

Larval fish are exposed to many physical variables in their environment, including gradients in light, temperature, and salinity. Menhaden larvae respond to temperature, as well as salinity gradients in the laboratory. Larvae ascend when exposed to temperature decreases from below, as well as temperature increases from above and below. Descent responses were not observed at any rate of increasing or decreasing temperature (De Vries et al., in review). The interaction of these variables, and their hierarchy of importance as they affect larval fish behavior is presently unclear, thus additional, more sophisticated experiments are necessary.

Transport of larval Atlantic menhaden and spot across the southeastern continental shelf to bays and estuaries is undoubtedly dependent upon numerous physical and biological conditions. Selective pressures to obtain sufficient food, escape predation, and remain in water warm enough for survival combine with those for enhanced shoreward transport to affect that portion of larval depth distribution under behavioral control. For larval menhaden, salinity gradients appear possible cues for eliciting depth selective behaviors. Salinity does not appear to be an important cue for behavioral regulation of spot larvae, though spot may be using other cues such as temperature or combinations of salinity and temperature gradients for shoreward transport.

\section{Acknowledgements}

This research was part of the South Atlantic Bight Recruitment Experiment (SABRE) sponsored by the NOAA Coastal Ocean Program. We are grateful to L. Settle for providing the CTD profiles and to Drs. J. Govoni and D. Checkley for critically reviewing the manuscript.

\section{References}

Blaxter, I.H.S., 1969. Visual thresholds and spectral sensitivity of flatfish larvae. $J$. Fxp. Biol., Vol. 51 , pp. $22 \mathrm{l}-230$.

Blaxter, J.H.S. \& J.R. Hunter, 1982. The biology of clupeoid fishes. Adv. Mar. Biol., Vol. 20, pp. 1-223.

Boehlert, G.W. \& B.C. Mundy, 1988. Roles of behavioral and physical factors in larval and juvenile fish recruitment to estuarine nursery areas. Am. Fish. Soc. Symp. Vol. 3, pp. 51-67.

Champalbert, G., C. Castelbon, L. Le Dircach, C. Macquart-Moulin \& G. Patriti, 1990. Experimental study of swimming activity and orientation of sole (Solea solea L.) larvae and juveniles: influence of endogenous rhythm, light, gravity, temperature and feeding. La Mer. Vol. 28, pp. 248-254.

Champalbert, G., C. Castelbon \& L. Le Direach-Boursier, 1992. Effects of salinity on swimming activity of larvae and juvenile sole (Solea solea L.). Experimental studies. Mar. Behav. Physiol., Vol. 21, pp. 121-143.

Checkley, D.M., Jr., S. Raman, G.L. Maillet \& K. M. Mason, 1988. Winter storm effects on the spawning and larval drift of a pelagic fish. Nature, Vol. 335, pp. 346-348.

Cushing, D.H., 1975. Marine ecology and fisheries. Cambridge University Press, Cambridge, 278 pp. 
Dunnett, C.W., 1964. New tables for multiple comparisons with a control. Biometrics, Vol. 20, pp. 282291.

Flores-Coto, C. \& S. M. Warlen, 1992. Spawning time, growth, and recruitment of larval spot Leiostomus xanthurus into a North Carolina estuary. Fish. Bull., Vol. 91, pp. 8-22.

Forward, R. B., Jr., 1987. Crustacean larval vertical migration: a perspective. In, Signposts in the sea, edited by W.F. Herrnkind \& A.B. Thistle, Florida State University Press, Tallahassee, pp. 29-44.

Forward, R.B., Jr., 1989. Behavioral responses of crustacean larvae to rates of salinity change. Biol. Bull. Vol. 176 , pp. $229-238$.

Forward, R.B., L.M. McKelvey, W.F. Hettler \& D.E. Hoss, 1993. Swimbladder inflation of the Atlantic menhaden Brevoortia tyrannus. Fish. Bull., Vol. 91, pp. 254-259.

Forward, R.B., Jr., W.F. Hettler \& D.E. Hoss, 1994. Swimbladder deflation of the Atlantic menhaden Brevoortia tyrannus. Fish. Bull., Vol. 92, pp. 641-646.

Govoni, J.J., 1993. Flux of larval fishes across frontal boundaries: examples from the Mississippi river plume front and the western Gulf Stream in winter. Bull. Mar. Sci, Vol. 53, pp. 538-566.

Govoni, J.J. \& L.J. Pietrafesa, 1994. Eulerian views of layered water currents, vertical distribution of some larval fishes, and inferred advective transport over the continental shelf off North Carolina, USA, in winter. Fish. Oceanogr., Vol. 3, pp. 120-132.

Hettler, W.F., 1981. Spawning and rearing Atlantic menhaden. Prog. Fish-Cult., Vol. 43, pp. 80-84.

Hettler, W.F., Jr. \& D.L. Barker, 1993. Distribution and abundance of larval fishes at two North Carolina Inlets. Estuarine Coastal Shelf Sci., Vol. 37, pp. 161-179.

Hettler, W.F. \& A.J. Chester, 1990. Temporal distribution of ichthyoplankton near Beaufort Inlet, North Carolina. Mar. Ecol. Prog. Ser., Vol. 68, pp. 157-168.

Hettler, W.F. \& A.B. Powell, 1981. Egg and larval fish production at the NMFS Beaufort Laboratory, N.C., USA. Rapp. P-v. Réun. Cons. Int. Explor. Mer, Vol. 178, pp. 501-503.

Hoss, D.E., D.M. Checkley, Jr. \& L.R. Settle, 1989. Diurnal buoyancy changes in larval Atlantic menhaden (Brevooria tyrannus). Rapp. P.-v. Réun. Cons. Int. Explor. Mer, Vol. 191, pp. 105-111.

Hunter, J.R., 1981. Feeding ecology and predation of marine fish larvae. In, Marine fish larvae, edited by R. Lasker, University of Washington Press, Seattle, pp. 33-77.

Hunter, J.R. \& C. Sanchez, 1976. Diel changes in swim bladder inflation of the larvae of the northern anchovy, Engraulis mordax. Fish. Bull., Vol. 74, pp. 847-855.

Kendall, A.W., Jr. \& J.W. Reintjes, 1975. Geographic and hydrographic distribution of Atlantic menhaden eggs and larvae along the middle Atlantic coast from RV Dolphin cruises, 1965-66. Fish. Bull., Vol. 73, pp. $317-335$.

Kjelson, M.A., G.N. Johnson, R.L. Garner \& J.P. Johnson, 1976. The horizontal-vertical distribution and sample variability of ichthyoplankton populations within the nearshore and offshore ecosystems of Onslow Bay. In, Atlantic Estuarine Fisheries Center Annual Report to ERDA (Energy Research and Development Administration), US National Marine Fisheries Service, Beaufort, North Carolina, USA, pp. 287-341.

Lasker, R. 1981. The role of a stable ocean in larval fish survival and subsequent recruitment. In, Marine fish larvae, edited by R. Lasker, University of Washington Press, Seatle, pp. 80-87.

Lawler, J.P., M.P. Weinstein, H.Y. Chen \& T.L. Englert, 1988. Modeling of physical and behavioral mechanisms influencing recruitment of spot and Atlantic croaker to the Cape Fear Estuary. Am. Fish. Soc. Symp. Vol. 3, pp. 115-131

Maillet, G.L. \& D.M. Checkley, Jr. 1991. Storm-related variation in the growth rate of otoliths of larval Atlantic menhaden Brevoortia tyrannus: a time series analysis of biological and physical variables and implications for larval growth and mortality. Mar. Ecol. Prog. Ser., Vol. 79, pp. 1-16.

Miller, J.M., 1988. Physical processes and mechanisms of coastal migrations in immature marine fishes. $\mathrm{Am}$. Fish. Soc. Symp. Vol. 3, pp. 68-76.

Miller, J.M., J.P. Reed \& L.P. Pietrafesa, 1984. Patterns, mechanisms and approaches to the study of migration of estuarine-dependent fish larvae and juveniles. In, Mechanisms of migration in fishes, edited by J.D. McCleave, G.P. Arnold, J.J. Dodson \& W.H. Neill, Plenum, New York, pp. 209-225.

Miller, J.M., L.B. Crowder \& M.L. Moser, 1985. Migration and utilization of estuarine nurseries by juvenile fishes: an evolutionary perspective. Contrib. Mar. Sci., Vol. 27 (Suppl.), pp. 338-352.

Munz, F.W., 1958. The photosensitive retinal pigments of fishes from relatively turbid coastal waters. J. Gen. Physiol., Vol. 42, pp. 445-459. 
Nelson, W.R., M.C. Ingham \& W.E. Schaaf, 1977. Larval transport and year-class strength of Atlantic menhaden, Brevoortia tyrannus. Fish. Bull., Vol. 75, pp. 23-41.

Norcross, B.L. \& R.F. Shaw, 1984. Oceanic and estuarine transport of fish eggs and larvae: a review. Trans. Am. Fish. Soc., Vol. 113, pp. 153-165.

Sogard, S.M., D.E. Hoss \& J.J. Govoni, 1987. Density and depth distribution of larval gulf menhaden, Brevoortia patronus, Atlantic croaker, Micropogonias undulatus, and spot, Leiostomus xanthurus, in the northern Gulf of Mexico. Fish. Bull., Vol. 85, pp. 601-609.

Warlen, S.M., 1992. Age, growth, and size distribution of larval Atlantic menhaden off North Carolina. Trans. Am. Fish. Soc., Vol. 121, pp. 588-598.

Warlen, S.M. \& J.S. Burke, 1990. Immigration of fall/winter spawning marine fishes into a North Carolina estuary. Estuaries, Vol. 13, pp. 453-461.

Warlen, S.M. \& A.J. Chester, 1985. Age, growth, and distribution of larval spot, Leiostomus xanthurus, off North Carolina. Fish. Bull., Vol. 83, pp. 587-599.

Weinstein, M.P., 1981. Plankton productivity and the distribution of fishes on the southeastern U.S. continental shelf. Science, Vol. 214, pp. 351-354.

Westerberg, H., 1984. The orientation of fish and the vertical stratification at fine- and micro-structure scales. Mechanisms of migration in fishes, edited by J.D. McCleave, G.P. Arnold, J.J. Dodson \& W.H. Neill, Plenum, New York, pp. 179-207.

Yoder, J.A., 1983. Statistical analysis of the distribution of fish eggs and larvac on the southeastern U.S. continental shelf with comments on oceanographic processes that may affect larval survival. Estuarine Coastal Shelf Sci., Vol. 17, pp. 637-650. 